enterprising manufacturers in this department have stepped forth to enrich the seventh exhibition of the Franklin Institute.

Respectfully,

$\begin{array}{ll}\text { Jno. Goodman, } & \text { Thomas C. Priee, } \\ \text { Geo. Handy, } & \text { Gro. Abrots. }\end{array}$

\title{
Report of the Judges on Philosophical Apparatus.
}

The committee on philosophical apparatus report, that they have examined the different articles submitted to them. They regret that no article conbeting for either of the premiums for mathematical and philosophical instruments, was offered. They were struck, however, with the beauty of execution of a self-registering thermometer, (for heat) made and deposited by J. Fisher, (h.m.) of Philadelphia. A surveying instrument, by $W . J$. Young, also attracted attention for its general usefulness and neatness of workmanship.

The committee would respectfully suggest as a matter of record, the providing a premium for accurately made thermometers, self-registering, as well as those of the ordinary kind, suitable for meteorological observations.

Philatelphia, October 6, 1831.

Martman Bache, A. D. BACIIE, Jos. Rousnt's, JR.

Supplementary Report from the same.

The committce on philosophical apparatus beg leave to make the further report, that among the articles coming within their province, was one not placed at the exhibition until after their first report. The article referred to is a balance of the most delicate kind used by apothecaries, made by J. Marshall, ( $h . m$.) of this city. The nicety of performance of this instrument, and the thorough neatness of its parts, render it highly worthy of notice. It has, when loaded with an ounce avoirdupois, proved, in the hands of the committee, to be sensible to less than the one-fiftieth part of a grain. The beam of this balance is eight inches in length, and of brass, the suspension knife-edge playing upon a concave curve of steel : the suspension of the scale hooks also knife-elge, the hooks being of steel. The scale chains, and uniting hooks, are of silver. The index is above the axis of the beam, and the adjustment made visible by the coincidence of the point of the index with a brass stem fixed above it. The stand of the balance is brass.

In recommending this instrument to notice, the cornmittee would suggest the propriety of offering such encouragement to the manufacturers of balances of this sort, as well as of the more delicate kind for philosophical purposes, at a future exhibition, as shall tend to cherish this useful branch of manufacture.

Philadelphia, October 11, 1831.

Hartman Bache,

A. D. Baohe. 